\title{
Postoperative analgesia with epidural butorphanol or tramadol in lower abdominal surgeries- A double blind comparative study
}

\author{
Aparna Abhijit Bagle ${ }^{1}$, Priyanka Gulia ${ }^{2}$, Sneha Sheelvanth ${ }^{3, *}$, Anagha Patil ${ }^{4}$, Tripti Nagdev ${ }^{5}$ \\ ${ }^{1}$ Professor, ${ }^{3,4,5}$ Junior Resident, Dept. of Anaesthesia, D. Y. Patil Medical College, Hospital and Research Centre, Pimpri, Pune, \\ Maharashtra, ${ }^{2}$ Senior Resident, Medanta Hospital, Gurgaon, Uttar Pradesh, India
}

*Corresponding Author:

Email: sneha.sheelvanth@gmail.com

Received: $09^{\text {th }}$ September, 2017

Accepted: $23^{\text {rd }}$ March, 2018

\begin{abstract}
Introduction: Post-operative analgesia in patients undergoing lower abdominal surgery is very essential for immediate postoperative pain relief which can be provided by oral or parenteral medication, epidural analgesia, local blocks etc. The combined spinal-epidural technique (CSE) has become increasingly popular in recent years. The study was designed to evaluate the efficacy of epidural butorphanol and tramadol for postoperative pain relief. After the surgical procedure and regression of spinal analgesia, the epidural catheter can be used to provide postoperative pain relief.

Materials and Methods: After permission from hospital ethics committee, study was conducted on 60 patients undergoing lower abdominal surgeries. Combined spinal epidural anaesthesia was planned in all these 60 patients using two segment technique.18 $\mathrm{G}$ epidural catheter was placed in L2-L3 space and spinal anaesthesia was given at L3-L4 space using 26 G Quincke's needle and $0.5 \%$ bupivacaine $3 \mathrm{ml}$.Sensory, motor block and hemodynamic parameters were monitored intraoperatively. Postoperatively along with hemodynamic parameters visual analogue score (VAS) was observed and at VAS > 4, study drug (either butorphanol $1 \mathrm{mg}$ or tramadol 50mg) was given through epidural catheter. Onset of analgesia, quality of analgesia, duration of analgesia, cardio-respiratory parameters and any side effects were monitored and documented.

Statistical Analysis: Data analysis was done using the SPSS (Statistical Package for the Social Science) Version 17 for window. Discussion: Mean onset of analgesia in Butorphanol group $(10.03 \pm 1.85 \mathrm{~min})$ was significantly faster than Tramadol group $(12.17 \pm 2.19 \mathrm{~min})[\mathrm{Z}=4.07, \mathrm{p}<0.0001]$. Mean duration of analgesia was significantly more in Tramadol group $(6.27 \pm 0.53 \mathrm{hrs})$ than with Butorphanol group $(3.40 \pm 0.42 \mathrm{hrs})$ [ $\mathrm{Z}=23.06, \mathrm{p}<0.0001]$. Quality of Analgesia and sedation score was better with Butorphanol group than Tramadol group.

Conclusion: Epidural butorphanol provides a rapid, excellent but shorter duration of analgesia when compared to epidural tramadol.
\end{abstract}

Keywords: Butorphanol, Tramadol, Postoperative analgesia, Epidural analgesia.

\section{Introduction}

"For all the happiness, mankind can gain is not in pleasure, but in rest from pain" - John Dryden (1631 1701)

Pain is best defined as "an unpleasant sensory and emotional experience associated with actual or potential tissue damage or described in terms of such damage'. Because of pain post-operative patients are unable to breathe adequately and cough effectively. Hence Effective pain control is vital for early mobilization and postoperative discharge. ${ }^{1}$ Various modalities have been tried to relieve the post-operative pain. The combined spinal-epidural technique (CSE) has become increasingly popular in recent years. It combines the advantages of both spinal and epidural technique by initially providing an intense sensory and motor block of rapid onset for operative procedure. After the surgical procedure and regression of spinal analgesia, the epidural catheter can be used to provide postoperative pain relief. $^{2}$

Epidural narcotics have been tried in various studies for treatment of post-operative pain. Opioids given orally undergo extensive first pass metabolism and intramuscular doses are absorbed unpredictably.
Epidural analgesia avoids these problems and excellent results have been obtained after using opioids via epidural route for control of postoperative pain. ${ }^{3}$ However, disadvantage with use of traditional drugs like morphine is that many side effects such as nausea, vomiting, pruritis, urinary retention, drug dependence and delayed respiratory depression have been reported. ${ }^{4}$ Butorphanol, a synthetic morphine derivative is a mixed agonist and antagonist non-narcotic opioid analgesic whereas tramadol is a synthetic 4-phenyl-piperdine analogue of codeine. ${ }^{5}$ Tramadol inhibits serotonin reuptake and norepinephrine reuptake, enhancing inhibitory effects on pain transmission in the spinal cord. Tramadol interacts with $\mu, \delta$ and $\kappa$ receptors where it purely exhibits agonistic activity. It has moderate affinity for $\mu$ receptor and weak affinity for delta and Kappa receptors. ${ }^{6}$

This present study was undertaken with the primary objective to compare the efficacy between epidural butorphanol and epidural tramadol for postoperative analgesia in lower abdominal surgeries. These drugs are most commonly used and easily available, and hence they were used in our study. The secondary objective was to see haemodynamic changes 
and any side effects associated with the drugs used in the study.

\section{Materials and Methods}

After permission from hospital ethics committee study was conducted on 60 patients undergoing lower abdominal surgeries in gynecology, general surgery and urology were randomly selected.

Sample Size: in the previous study by Ruchie P, duration of analgesia in epidural tramadol group was $6.25+/-1.58$ hours and in the epidural butorphanol group it was $5.35+/-0.29$ hours. To get at least this much of difference in duration of analgesia, required sample size was calculated using Win Epi software with confidence interval of $95 \%$ and power of study $80 \%$. Minimum sample size calculated was 52(26 in each group), but considering exclusion, drop out and lost to follow up, we took sample size of 60. (30 in each group)

Inclusion criteria: Physical status ASA I and II between 20 to 60 years undergoing lower abdominal surgeries.

Exclusion criteria: All patients above ASA-III grade, Coagulation defects, severe haemorrhage or shock, Local inflammation / infection, drug allergy, Patient refusal.

Two groups were made Group T: Injection Tramadol (T) and Group B: Injection Butorphanol (B)

During preoperative visit patient's detailed history, general physical examination and systemic examination was carried out. Age, sex and weight were recorded. Basic investigations like complete hemogram, random blood sugar, Prothrombin time, International normalized ratio, blood urea, serum creatinine, Chest X-ray and Electrocardiogram were carried out. During pre anaesthesia visit, all patients were informed about anaesthesia technique and research study and their written informed consent was taken. Patients were taught to assess the intensity of pain using visual analogue scale (VAS)

$$
\begin{aligned}
& 012345678910 \\
& \text { No pain at all } \quad \text { Worst pain imaginable }
\end{aligned}
$$

0-3 - Mild Pain

3-7 - Moderate Pain

$>7$ - Severe Pain
All the patients received tablet alprazolam $0.5 \mathrm{mg}$ orally on the previous night of surgery.

Patients were kept nil orally for $8 \mathrm{hrs}$ before surgery.

All the patients were preloaded with $10 \mathrm{ml} / \mathrm{kg}$ infusion of Ringer Lactate solution.

All patients were administered combined spinal epidural anaesthesia using 2 segment technique. Baseline pulse, systolic and diastolic blood pressure (SBP and DBP) and respiratory rate were recorded. Under all aseptic precautions, local infiltration with lignocaine was done and $18 \mathrm{G}$ epidural catheter was introduced in L2-L3 space through Tuohy's epidural needle.

$3 \mathrm{ml}$ of $2 \%$ lignocaine with adrenaline given as test dose.

Then subarachnoid anaesthesia was given in L3-L4 space using 26G Quincke's needle and $3 \mathrm{ml}$ of $0.5 \%$ heavy bupivacaine. Level of sensory and motor block and haemodynamic parameters were monitored intraoperatively.

In the post-operative period, at Visual Analogue Score (VAS) of $>4$, patients were administered $1 \mathrm{mg}$ of butorphanol diluted to $10 \mathrm{ml}$ with normal saline, in group-B (Butorphanol) or $50 \mathrm{mg}$ of tramadol diluted to $10 \mathrm{ml}$ with normal saline, in group- $\mathrm{T}$ (Tramadol) through epidural catheter. Both the drugs were preservative free. After giving epidural opioid (butorphanol/tramadol) pulse rate, blood pressure (SBP and DBP), respiratory rate and sedation score were recorded at baseline, $30 \mathrm{~min}, 1 \mathrm{hr} ., 2 \mathrm{hr}$., $4 \mathrm{hr}$., $6 \mathrm{hr}$. and $8 \mathrm{hr}$.

Following clinical parameters were studied:

1. Onset of analgesia calculated as the time of giving of epidural drug and beginning of pain relief.

2. Duration of analgesia was calculated as the time gap between the epidural injection of drug and the time when patient asked for rescue analgesia.

3. Quality of analgesia using Verbal Response Score

4. Level of consciousness using Sedation Score

5. Cardio-respiratory parameter (PR, SBP, DBP, RR)

6. Side effects (nausea, vomiting, pruritis, respiratory depression, hypotension)

7. No local anaesthetic agents were added to the narcotic given epidurally.

8. Inj.Diclofenac $75 \mathrm{mg}$ was given IV as rescue analgesia.

Assessment of pain relief was done using five point verbal response score. ${ }^{6}$

\section{Five point verbal response score (VRS)}

\begin{tabular}{|c|l|l|}
\hline (VRS) & \multicolumn{2}{|c|}{ Subjective } \\
\hline 0 & No pain relief & $0 \%$ pain relief \\
\hline 1 & Little(poor) pain relief & $25 \%$ pain relief \\
\hline 2 & Some(fair) pain relief & $50 \%$ pain relief \\
\hline 3 & $\begin{array}{l}\text { A lot of(good) pain } \\
\text { relief }\end{array}$ & $75 \%$ pain relief \\
\hline 4 & complete pain relief & $100 \%$ pain relief \\
\hline
\end{tabular}


Level of consciousness was assessed by Sedation Score

0 -awake

1-slightly drowsy

2-asleep but easily arousable

3 -fully asleep and not arousable.

\section{Statistical Analysis}

Data analysis was done using the SPSS (Statistical Package for the Social Science) Version 17 for window. The $\mathrm{t}$ test, Mann Whitney test (MW), proportion test was used to find significant difference in age, weight, onset of analgesia, duration, quality of analgesia, vital parameters, sedation score and side effects in study groups. A probability value of 0.05 or less was accepted as the level of statistical significance.

\section{Consort 2010 Flow Diagram}

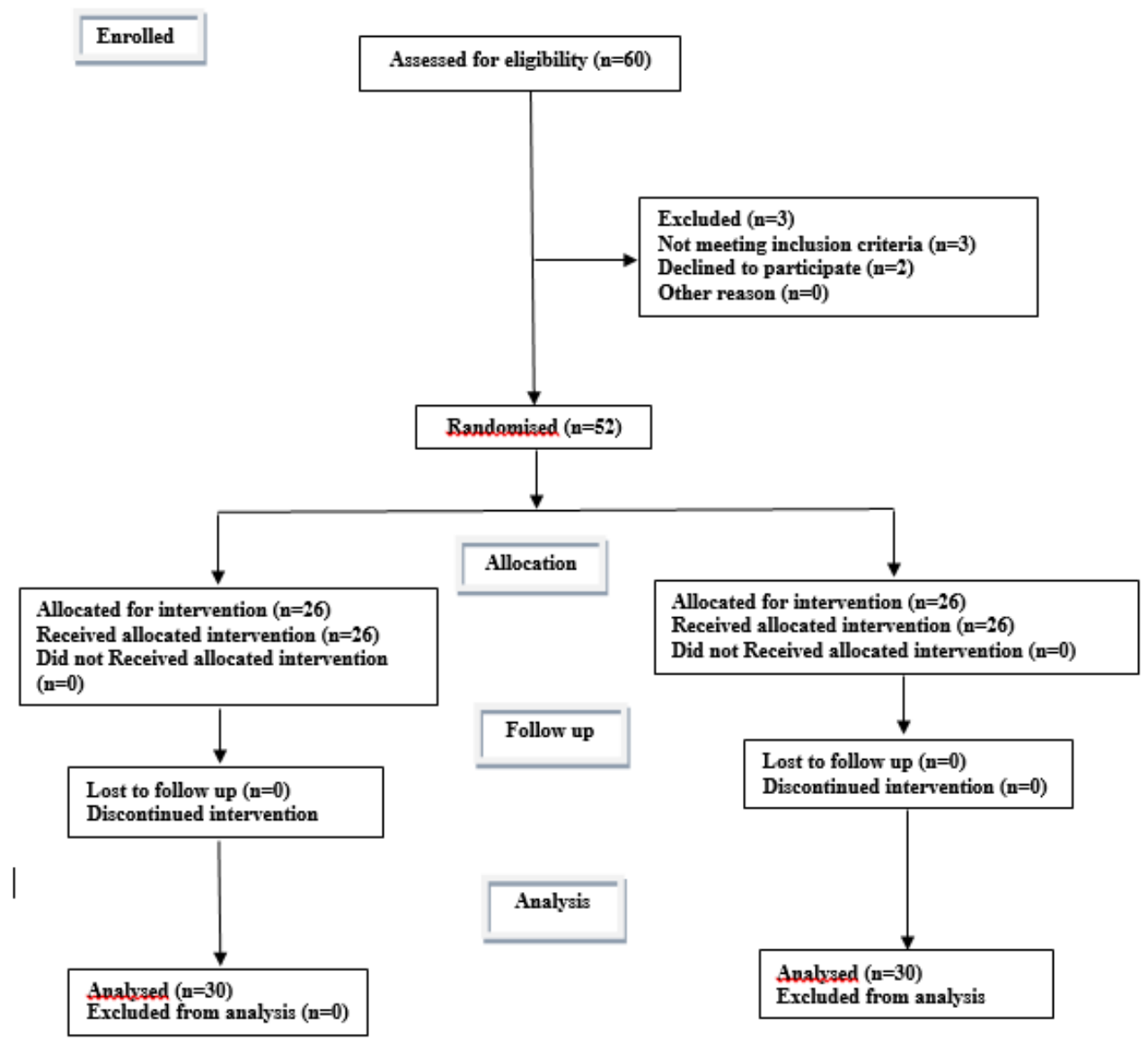

\section{Results}

Table 1: Comparison of age, weight and sex in study groups

\begin{tabular}{|l|l|l|l|l|}
\hline Parameters & $\begin{array}{l}\text { Group T } \\
(\mathbf{n = 3 0 )}\end{array}$ & $\begin{array}{l}\text { Group B } \\
(\mathbf{n = 3 0})\end{array}$ & P Value & Significance \\
\hline Age (Year) & $38.53+/-9.13$ & $42.67+/-11.62$ & 0.134 & Not significant \\
\hline Weight(kilogram) & $60.63+/-6.33$ & $58.63+/-6.33$ & 0.226 & Not significant \\
\hline Sex & & $10(33 \%)$ & 0.653 & Not significant \\
Male & $14(47 \%)$ & $10(67 \%)$ & 0.752 & Not significant \\
Female & $16(53 \%)$ & $20(76)$ & & \\
\hline
\end{tabular}

Group $\mathrm{T}$ and Group B were comparable with respect to age, weight and sex distribution performed. The haemodynamic parameters were clinically stable in both the groups. 
Table 2: Comparison of onset of analgesia in study groups

\begin{tabular}{|c|c|c|}
\hline $\begin{array}{c}\text { Onset of } \\
\text { analgesia(minutes) }\end{array}$ & Group T & Group B \\
\hline $0-3$ & $0(0 \%)$ & $0(0 \%)$ \\
\hline $4-6$ & $0(0 \%)$ & $1(3 \%)$ \\
\hline $7-9$ & $4(13 \%)$ & $11(37 \%)$ \\
\hline $10-12$ & $9(30 \%)$ & $15(50 \%)$ \\
\hline $13-15$ & $17(57 \%)$ & $3(10 \%)$ \\
\hline Mean & $12.17+/-2.19$ & $10.03+/-1.85$ \\
\hline
\end{tabular}

In $40 \%$ of patients onset of analgesia was within 10 minutes in Group B as compared to group T (13\%).Mean onset of analgesia in Group B $(10.03 \pm 1.85 \mathrm{~min})$ was significantly faster than Group $\mathrm{T}(12.17 \pm 2.19 \mathrm{~min})[\mathrm{Z}=$ $4.07, \mathrm{p}<0.0001]$.

Table 3: Comparison of quality of analgesia in study groups (Verbal Response Score)

\begin{tabular}{|c|l|c|c|c|}
\hline $\begin{array}{c}\text { VRS } \\
\text { score }\end{array}$ & Quality of Analgesia & $\begin{array}{c}\text { Group T } \\
(\mathbf{n = 3 0})\end{array}$ & $\begin{array}{c}\text { Group B } \\
(\mathbf{n = 3 0})\end{array}$ & $\mathbf{P}$ \\
\hline 0 & No pain relief & 0 & 0 & - \\
\hline 1 & Little(poor) pain relief & 0 & 0 & - \\
\hline 2 & Some(fair) pain relief & $2(6 \%)$ & 0 & 0.472 \\
\hline 3 & A lot of(good) pain relief & $20(67 \%)$ & $9(30 \%)$ & 0.509 \\
\hline 4 & Complete pain relief & $8(27 \%)$ & $21(70 \%)$ & 0.002 \\
\hline
\end{tabular}

Quality of Analgesia was better with Group B than Group T as complete pain relief was there in $70 \%$ of Group B patients while only $27 \%$ patients in Group T experienced complete pain relief.

Table 4: Comparison of duration of analgesia in study groups

\begin{tabular}{|l|c|c|c|c|c|c|}
\hline Analgesia & \multicolumn{2}{|c|}{ Group T (n=30) } & \multicolumn{2}{c|}{ Group B (n=30) } & Z Value & P Value \\
\cline { 2 - 5 } & Mean & SD & Mean & SD & & \\
\hline Duration $(\mathrm{Hrs})$ & 6.27 & 0.53 & 3.40 & 0.42 & 23.06 & $<0.0001$ \\
\hline
\end{tabular}

The above table shows comparison of duration of analgesia (hrs) among two Groups. Mean and Standard deviation were calculated. Mean duration of analgesia (hrs) was 6.27 (S.D. of \pm 0.53 ) hours in Group T and in group B mean duration of analgesia (hrs) was 3.40 ( $\mathrm{S} . \mathrm{D} \pm 0.42$ ) hours. This mean duration of analgesia (hrs) was analyzed quantitatively within groups as shown in above table. The $\mathrm{Z}$ value was 23.06 , which was statistically highly significant $(\mathrm{p}<0.0001)$.

Table 5: Comparison of sedation score in study groups

\begin{tabular}{|l|c|c|c|c|c|c|}
\hline \multirow{2}{*}{$\begin{array}{c}\text { Sedation } \\
\text { score }\end{array}$} & \multicolumn{2}{|c|}{ Group T $(\mathbf{n}=\mathbf{3 0})$} & \multicolumn{2}{c|}{ Group B $(\mathbf{n}=\mathbf{3 0})$} & \multirow{2}{*}{ Z Value } & P Value \\
\cline { 2 - 5 } Baseline & 0 & 0 & 0 & 0 & 0 & $>0.05$ \\
\hline At 30 min & 1.33 & 0.96 & 1.40 & 0.93 & 0.27 & $>0.05$ \\
\hline At 60 min & 1.27 & 0.69 & 1.80 & 0.99 & 0.019 & $<0.05$ \\
\hline At 2 Hrs & 1.40 & 0.89 & 1.53 & 0.86 & 0.59 & $>0.05$ \\
\hline At 4 Hrs & 0.67 & 0.61 & 0.87 & 0.51 & 0.174 & $>0.05$ \\
\hline At 6 Hrs & 0 & 0 & 0 & 0 & 0 & $>0.05$ \\
\hline At 8 Hrs & 0 & 0 & 0 & 0 & 0 & $>0.05$ \\
\hline
\end{tabular}

Better sedation was seen with butorphanol group at different time intervals as compared to tramadol. At 60 min mean sedation score with butorphanol $(1.80 \pm 0.99)$ was significantly higher than when compared to tramadol $(1.27 \pm$ $0.69)[\mathrm{Z}=2.41, \mathrm{p}<0.05]$. 


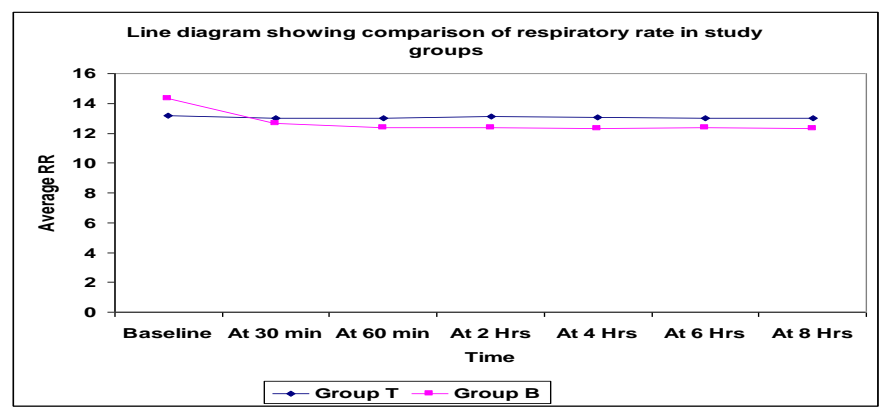

Fig. 1: Line diagram showing comparison of Respiratory rates in study groups

Mean respiratory rate was 13.20 (S.D. \pm 1.61 ) at baseline in Group T, which was same till the end. At $2 \mathrm{hrs}$ 13.10 (S.D. \pm 1.39 ) and at $8 \mathrm{hrs}$ mean respiratory rate was 13.03 (S.D. \pm 1.45 ). Mean respiratory rate in Group B at baseline was 14.33 (S.D. \pm 1.37 ) which was 12.37 (S.D. \pm 1.27 ) at 2 hrs. Mean respiratory rate at 8 hrs was 12.30 (S.D. \pm 1.29 ) This Mean respiratory rate was analyzed quantitatively within groups for each stage from baseline to 8 hrs as shown in above table. The $\mathrm{Z}$ value was 2.94 at baseline, 2.12 at $2 \mathrm{hrs}, 2.07$ at $4 \mathrm{hrs}$ and 2.07 at $8 \mathrm{hrs}$ stage which were statistically significant $(\mathrm{p}<0.05)$ but was not clinically significant with patients showing no signs of clinical desaturation or hypoxia.

Table 6: Comparison of side effect in study groups

\begin{tabular}{|l|c|c|c|c|}
\hline Side effect & Group T $(\mathbf{n}=\mathbf{3 0})$ & Group B $(\mathbf{n}=\mathbf{3 0})$ & Z Value & P Value \\
\hline Nausea & $6(20 \%)$ & $2(6.67 \%)$ & 1.55 & $>0.05$ \\
\hline Vomiting & $4(13.33 \%)$ & $2(6.67 \%)$ & 0.87 & $>0.05$ \\
\hline
\end{tabular}

It was observed that patients in tramadol group had more nausea and vomiting as compared to butorphanol but the difference was statistically not significant. None of the patients in both groups had pruritis, cardiorespiratory depression.

\section{Discussion}

The prime function of anesthesiologist is to relieve pain. Postoperative analgesia decreases tachycardia, tachypnea and oxygen consumption which is useful in patients with ischemic heart disease, anemia and cardiac failure. Postoperative analgesia minimizes chances of deep vein thrombosis and attenuates neurohumoral stress response to surgery and helps in wound healing and also helps in better postoperative ventilation of patient. ${ }^{7}$

Opioids administered in epidural space can enter the CSF by penetrating the Dura, can remain in epidural fat and can leave epidural space as a result of uptake by radicular arteries and epidural venous plexus. The onset of action, analgesic potency and duration of analgesia are related to CSF opioid concentration. The concentration of epidurally administered opioids into CSF and then into spinal cord is both determined by lipid solubility of the drug. The more lipid soluble an opioid is, the more rapid its absorption into CSF and then into the spinal cord and also shorter the time for the onset of its effect. ${ }^{8}$ This is an effective way of analgesia as these drugs get deposited near the site where they will exert their effect. Opioid receptors are found in substantia gelatinosa, which is the binding site for epidural opioids. ${ }^{9}$
Opioids which are hydrophilic such as morphine tend to stay in the CSF and then migrate rostrally whereas lipophilic opioids such as fentanyl are prone to rapid diffusion into the lipid rich areas in spinal cord and exhibit little CSF migration. The various side effects caused due to spinal opioids is due to migration of these opioids into the CSF where they can act on the respiratory centres of the brain or may activate the chemoreceptor trigger zone located in the caudal end of the fourth ventricle causing nausea and vomiting. ${ }^{10}$

Studies have shown that Tramadol in doses of 100 $\mathrm{mg}$ and above has side effects like nausea, vomiting, hypotension etc. Butorphanol is more potent than morphine and pethidine and has been employed in postoperative pain relief ${ }^{9}$. With doses more than $1 \mathrm{mg}$, increase in duration of analgesia and side effects (nausea, vomiting, pruritis and somnolence) was observed. ${ }^{10-12}$

In our study, onset of analgesia as well as quality of analgesia was better in Group B as compared to Group T. Singh B in 2011 did a study to compare efficacy of epidural butorphanol $(1 \mathrm{mg})$ and tramadol $(50 \mathrm{mg})$ and found that onset of action was faster with butorphanol than tramadol and also quality of analgesia was better with butorphanol while duration of analgesia was longer with epidural tramadol. ${ }^{13}$

We observed that duration of analgesia (hrs) was significantly less in butorphanol group as compared to Tramadol group, which was similar to the findings by Singh S, Gupta R and Rathi P. ${ }^{13-15}$ Singh S in 2011 concluded that duration of analgesia was more with tramadol than butorphanol. Gupta $\mathrm{N}$ studied analgesic 
efficacy of intravenous tramadol $(1 \mathrm{mg} / \mathrm{kg})$ and butorphanol $(1 \mathrm{mg})$ and found that quality of analgesia was better in butorphanol group. ${ }^{16}$

The systolic and diastolic blood pressure were analyzed quantitatively within groups for each stage from baseline to $8 \mathrm{hrs}$. The difference was statistically not significant within groups. (P 0.05), even though there is mild fall in pulse rate and respiratory rate with butorphanol group, the cardiovascular and respiratory parameters were clinically stable in both groups. This was comparable to the findings of Singh S and Gupta R. ${ }^{13,14}$

Better sedation was seen in butorphanol group as compared to tramadol group. In the study at the end of 1 hour difference between sedation score of butorphanol and tramadol group was statistically significant $(\mathrm{p}<0.05)$. In a study by Abbound, Singh $S$, Gupta R, Gupta N and sedation score was significantly higher with Butorphanol compared to tramadol, may be due to its effect on kappa receptor and this is consistent with our study. ${ }^{7,13-17}$

Group B patients had side effects like nausea (6\%) and vomiting (4\%) which were less when compared to group $\mathrm{T}$, where $20 \%$ of patients had nausea and $13 \%$ had vomiting. The différence was statistically insignifiant ( $p>0.05)$. Gupta $R$ in 2011 compared the efficacy of epidural butorphanol and tramadol and found that nausea and vomiting was found in tramadol group only. ${ }^{12}$

Palacios et $\mathrm{al}^{17}$ found that no patients in their study group receiving epidural butorphanol developed clinically important change in haemodynamic parameters while study by Rathie Pinky et $\mathrm{al}^{45}$ showed that, even tramadol does not have significant alterations in these parameters.

\section{Conclusion}

1. Epidural Butorphanol provides a rapid, excellent but shorter duration of analgesia when compared to epidural tramadol.

2. Epidural Butorphanol had lesser side effects like nausea and vomiting.

3. Quality of analgesia in terms of patient satisfaction is also better with epidural Butorphanol.

From our study, it appears both epidural butorphanol $(1 \mathrm{mg})$ and epidural tramadol $(50 \mathrm{mg})$ have good efficacy except duration of action, which is shorter for butorphanol. Butorphanol also has better sedation score which is an additional advantage in the post-operative period.

\section{References}

1. Wu CL. Acute postoperative pain. In: Miller RD, editor. Anesthesia, $6^{\text {th }}$ ed. Pennsylvania: Churchill Livingstone; 2005. p. 2764-5

2. Cousins MJ, Mather Laurence E. Intrathecal and epidural administration of opioids. Anaesthesiology 1984; 65:276310.
3. Morgan M. The rational use of intrathecal and extradural opioids. Br J Anaesth 1989;63:165-88.

4. Nimmo SM. Benefit and outcome after epidural analgesia. Continuing Education in Anaesthesia, Critical Care and Pain 2004;4:44-7.

5. Vandam Leroy D. Drug therapy: Butorphanol. Eng J Med 1980;302:381-84.

6. Delilkan A.E, Vijayan R.Epidural tramadol for postoperative pain relief. Journal of the Association of Anaesthetists of Great Britain 1993;48:328-31.

7. Abbound TK, Moore M, Zhu J, Murakawa K, Minehart M, Longhitano M, et al. Epidural Butorphanol or morphine for the relief of post-caesarean section pain: ventilatory responses to carbon dioxide. AnaesthAnalg. 1987 Sep;66:887-93.

8. Gut-Stein HB, Huda A. Opioid analgesics. In: Hardman G, Limbird LE, Gilman AG, editors. Goodman and Gilman's the pharmacological basis of therapeutics. $10^{\text {th }}$ Ed. New York: McGraw Hill, 2001.p337-619.

9. Stoelting RK, editor. Pharmacology and Physiology in Anaesthesia Practice. $3^{\text {rd }}$ Ed, Philadelphia: LippincottRaven,1999.p77-112.

10. Jablonka DH, Davis PJ. Opioid in PediatricAnaesthesia. AnaesthesiologyClin N Am. 2005;23:621-34.

11. Dhimar AA, Patel M, Swadia VN, Desai DJ. Epidural Butorphanol. Comparison of two different doses for lower limb orthopaedic surgery. J AnaesthClinPharmacol. 2006;22:47-52.

12. Naulty JS, Weintraus S, McMohan J, Ostheimer GW, Hunt C, Chantigian R. Epidural butorphanol for post cesarean delivery pain management. Anaesthesiology 1984;61:415.

13. Singh B, Nihlani S. Post-operative analgesia: A comparative study of Epidural Butorphanol and Epidural Tramadol. Journal of Advance Researches in Biological Sciences 2011;3:86-9.

14. Gupta R, Kaur S, Singh S, Aujla KS. A comparison of epidural butorphanol and tramadol for postoperative analgesia using CSEA technique. J Anaesthesiology Clinical Pharmacology. 2011;27:35-8.

15. Rathie P, Verma RS, Jatav TS, Kabra A. Post-operative pain relief by epidural tramadol. Ind J Anaesth 1998;42:26-31.

16. Gupta N, Anand S, Gulati S, Gupta S, Kapoor BB.Comparison of tramadol and butorphanol for analgesic efficacy and safety. JK Science: Journal of Medical Education and Research 2008;10:132-4.

17. Malik P, Manchanda C, Malhotra N. Comparative Evaluation of Epidural Fentanyl and Butorphanol for Postoperative Analgesia. J AnaesthClinPharmacol 2006;22:377-82. 